Haya: The Saudi Journal of Life Sciences

Abbreviated Key Title: Haya Saudi J Life Sci ISSN 2415-623X (Print) |ISSN 2415-6221 (Online) Scholars Middle East Publishers, Dubai, United Arab Emirates Journal homepage: https://saudijournals.com/sjls

Original Research Article

\title{
Renewal of Healthcare Funding Systems by National Health Insurance in the Kingdom of Saudi Arabia (NHI)
}

\author{
Prof. Dr. Sharifah Ezat Wan Puteh", Prof. Dr. Azimatun Noor Aizuddin, Abdulaziz Abdullah Al Salem
}

Department of Community Health, Faculity of Medicine, UKM

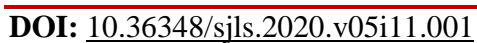

| Received: 30.10 .2020 | Accepted: 14.11.2020 | Published: 19.11.2020

*Corresponding author: Prof. Dr. Sharifah Ezat Wan Puteh

\section{Abstract}

The aim of this paper is to discuss the current structure of the Saudi health care system, and to assess financing healthcare services in the Kingdom of Saudi Arabia (KSA) by implementing national health insurance. The paper focuses on improving Saudi Arabia's health care system as a national health insurance system is being introduced. The aim of this policy reform is to increase investment in the healthcare sector by the private sector and to reduce government costs for health services. Access to healthcare, sustainability, costs and quality of care, adaptation of new technologies and the use of health services are all expected to have a positive impact. We are reviewing the current health literature and the latest health reform of Saudi Arabia. In this area, the importance of public health: improving the health system is intended to improve the outcomes of community health. Whether it will have the desired impact will be clear as Saudi Arabia embarks on this move. In addition, if Saudi Arabia succeeds in providing high-quality healthcare to this segment of the population, expatriate healthcare in different countries is a challenge; other countries will follow the Saudi model. The purpose of this study is to analyze the existing structure of Saudi health systems, to assess the funding programs for health care in the Kingdom of Saudi Arabia (KSA) by introducing national health insurance schemes and to propose improvements.

Keywords: Renovation, Financing, Healthcare, System, and Health Insurance.

Copyright @ 2020: This is an open-access article distributed under the terms of the Creative Commons Attribution license which permits unrestricted use, distribution, and reproduction in any medium for non-commercial use (NonCommercial, or CC-BY-NC) provided the original author and source are credited.

\section{INTRODUCTION}

The WHO World Health Study 2013 calls for research into the benefits and challenges of universal health coverage. In 2005, all WHO Member States made a pledge to universal health coverage. Universal health coverage ensures that everyone has access to the quality of health care they need when they need it, without risking financial distress paying for them. This needs a powerful, reliable, well-managed and sensitive health system; access to vital medicines and technologies; and adequate, motivated and well-trained health staff. The problem for most countries is how to extend health services to meet growing needs of limited resources [1]. As many countries are working to achieve this goal, there is no popular response as to how to achieve it. Local factors play a role because each country has its own specific social and political characteristics that call for personalized solutions.

Health costs increase internationally, and decision-makers are faced with the challenge of enforcing the right health policy to ensure good quality, cost-effective health services. Any health policy should aim at improving the status of health, achieving justice and productivity within political limitations. Some countries are preparing significant healthcare system improvements to achieve these goals. Health reform is complicated intrinsically by priorities that are mutually conflicting and cannot always be matched. For example, providing affordable healthcare can be seen as conflicting with the aim of providing high-quality healthcare [2]. The broad diversity between countries in their social values, cultural trends and the degree of social and economic growth, together with the inherent difficulty of reform developing and enforcing them, lack a common consensus on health-reporting concept [3]. With all these in mind, the WHO identifies a change that will intentionally, sustainably and systematically turn one or more major health subsystems into a systemic transformation mechanism [3].

In addition to its unique characteristics of high population growth and increased rates of chronic diseases, Saudi Arabia is facing global trends in rising 
healthcare costs. K.S.A. may be considered a welfare state in that it has historically offered free healthcare and other social services to the community. Recently, however, the government has realized that this model is unsustainable in the long run, particularly as expatriates make up a large proportion of the population and provide increased demand for healthcare services. As a result, Saudi decision-makers are seeking to change the healthcare system. This paper discusses Saudi Arabia's health system, the challenges it faces, and the proposed change, with the greatest focus on NHI. Saudi Arabia is the largest country in the Gulf Council countries and is now switching the health care system from the universal health care system to the universal insurance system.

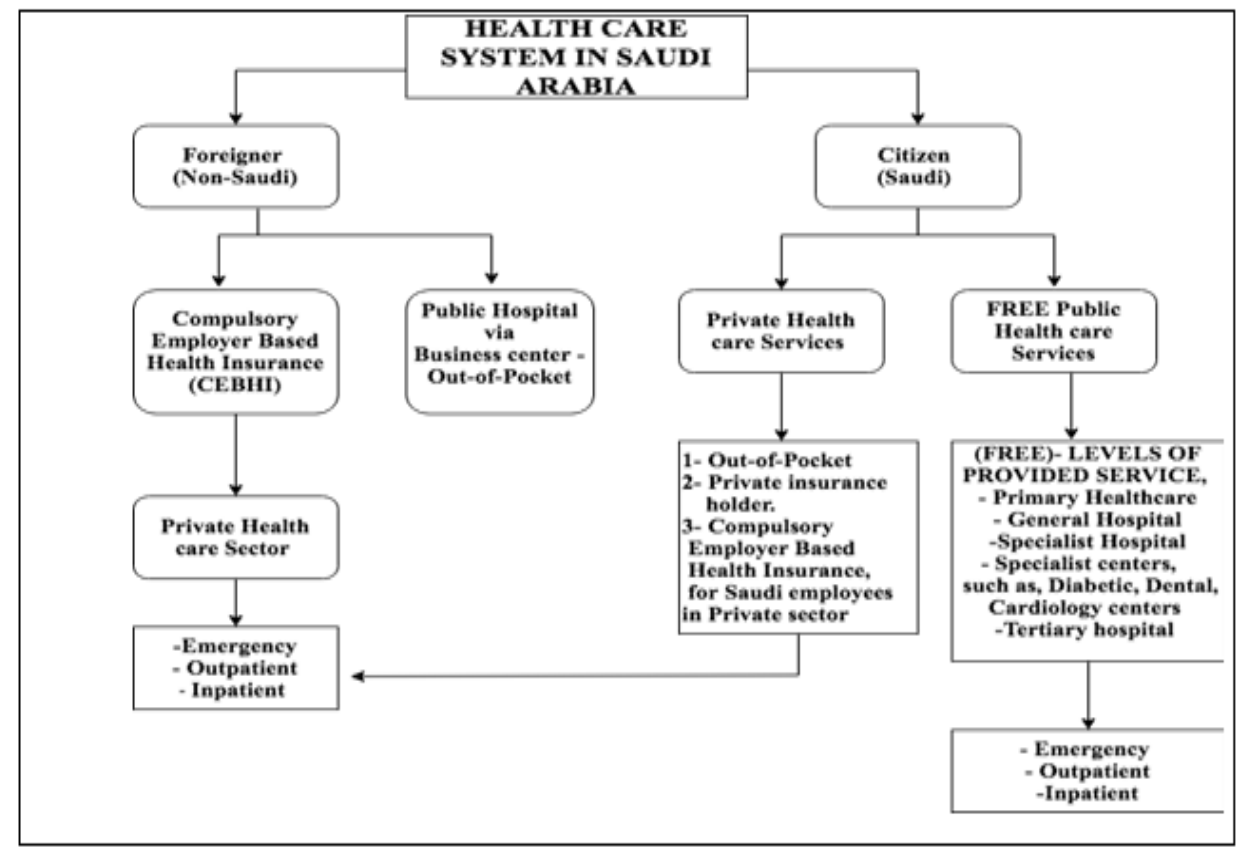

Fig-1.1: Health care system in Saudi Arabia

\section{OBJECTIVES}

To explore the current structure of the Saudi health care system, and to assess financing healthcare services in the Kingdom of Saudi Arabia (KSA) by implementing national health insurance.

\section{LITERATURE REVIEW \\ Healthcare in Saudi Arabia}

In Saudi Arabia 55\% of the population are males; the majority of the population is under 25 years of age, the total median age is 26 (27 years for males and 24.8 years for females) and life expectancy at birth is 74.6 years. Population growth rate is $1.5 \%$ annually and birth rate is 19.0 per 1000 population [4]. Despite the rapidly growing young population, the average income of nationals is increasing. This led to an increased demand on infra-structure and services especially healthcare. Expenditure on health in 2011 was 3.7 of GDP [5]. Saudi Arabia, which compromises two-thirds of the population of the GCC, is the largest spender on health in the region. However, this spending is not proportional with its population share in the region. The Saudi population makes up $67 \%$ of the GCC population while its health expenditure is only $54 \%$ of the GCC's health expenditure. The UAE, Kuwait, Qatar and Bahrain have a higher share of healthcare spending in GCC compared to their population [6].

The rate of communicable diseases has decreased but there is an increased rate of noncommunicable diseases, especially cardiovascular diseases and diabetes. Road traffic accidents are one of the leading causes of death in younger adult males. The estimated road traffic death rate per 100,000 populations in 2010 was 24.8 , which is among the highest in the world [7]. KSA hosts more than 3 million pilgrims from more than 183 countries annually during the holy pilgrimage season (Hajj). The gathering of this large mass poses a variety of health risks including those due to infectious diseases such as seasonal, respiratory, gastrointestinal and food borne illnesses [8]. Although KSA has the largest number of hospitals and clinics in the GCC, it still trails behind the developed countries with regard to important healthcare indicators, including the following: hospital bed capacity (2.2 per 1000 capita), physicians (2.18 per 1000 capita), and nurses (4.1 per 1000 capita) [8].

\section{Health Systems, Problems and Reforms in Saudi Arabia}

In K.S.A, the public sector remains the main source of healthcare funding accounting for almost $70 \%$. The private sector's contribution is increasing 
steadily although at a slow rate. The new regulatory reforms have encouraged greater participation of the private sector. Consequently, the public sector's share in healthcare spending has decreased from $73 \%$ in 2000 to $70.9 \%$ in $2009[6]$.

K.S.A. faces a number of healthcare challenges such as increasing costs, treatment demands and extra demand on quality health services. With the combined factors of high population growth rate and an increase in lifestyle related disease, healthcare costs are likely to increase over the coming years. It is estimated that by 2025 health expenditure in the region will reach $\$ 60$ billion. The demand for treatment, especially cardiovascular diseases and diabetes related ailments are projected to increase over the coming years. There will also be an increased demand for hospital beds and patients' expectations of healthcare quality are increasing $[9,10]$. The shortage of medical professionals is another major problem in the kingdom. There are very limited medical education options in the region and healthcare organizations depend on expatriates, who represent $40-80 \%$, depending on the country, of the total workforce. Currently around 20 qualified physicians serve every 10,000 people, compared to approximately 27 doctors in the US and UK systems indicating a shortage of about 180,000 specialists [11]. Although there has been major investment in the healthcare system in K.S.A, many residents remain unsatisfied with the availability and quality of care at government-run hospitals and clinics [9]. The policymakers' objective is to increase the role of the private sector in healthcare both as a financer and a provider. The health system in the kingdom will be facing challenges as it transitions into health insurance. Generally Saudi government lack experience and skills to build and operate complex health insurance businesses. The biggest challenge will therefore be to find qualified professionals to build and manage complex health insurance businesses in the region. Furthermore, there is lack of standard quality measures for healthcare in the Gulf Region [10].

Saudi Government realizes the challenges that they face and are all working on improving their health system to meet the future needs. Saudi Arabia has announced plan to expand healthcare infrastructure. A number of international players entered the kingdom health market with advanced facilities and technologies and play various roles operating individually, in partnerships with the government or as managers of facilities. These countries are also investing in healthcare technology. E-health services are expected to make the delivery of health services more cost effective. Medical tourism is another area that kingdom is targeting by building medical cities. Also, the Ministry of Health is introducing policies to encourage accreditation of existing health facilities by internationally recognized bodies such as the Joint Commission International (JCI). This step will improve quality standards and may also enhance medical tourism. Increasing the participation of the private sector through health insurance is an important approach that government is taking to decrease dependence on public funds. In addition, K.S.A. is building its education infrastructure to enable more nationals to enter the profession of healthcare and consequently decrease their reliance on foreign health professional [6].

\section{Health System and Financing in Saudi Arabia}

The Saudi constitution states that the government provides all citizens and expatriates working within the public sector with full and free access to all public health services. The Ministry of Health $(\mathrm{MOH})$ finances, controls, manage and supervises the public health sector. $\mathrm{MOH}$ provides health services at three levels: primary, secondary and tertiary. In 1980, in accordance with the Alma-Ata declaration, the Ministry adopted the PHC approach instead of the preexisting curative model. Adapting this model has resulted in reducing visits to outpatient clinics, reduced duplication of services, reduced the cost of medication and improved prescribing practices $[12,13]$. The $\mathrm{MOH}$ also provides health free health services to pilgrims during Hajj season. The pilgrimage season creates an extra demand on health services; the government has created a healthcare infrastructure that includes 177 primary medical clinics and 27 hospitals in the vicinity of the pilgrimage areas $[14,15]$.

Health care financing in Saudi Arabia is provided from the government's annual budget, which is mainly derived from oil revenue. There are two main healthcare suppliers in the kingdom: the government sector and the private sector.

The government sector provides healthcare free to all Saudi citizens and foreigners who work in the public sector. The Ministry of Health $(\mathrm{MOH})$ provides $60 \%$ of the total health services, through 13 health directories in Saudi Arabia and is the major government provider. The other governmental healthcare providers provide comprehensive health services to their targeted population, usually employees and their dependents, and represent $20 \%$ of health services. Their budgets are allocated directly from the Ministry of Finance through their respective ministries and agencies. These agencies include:

- Ministry of Interior

- Ministry of Defense

- National Guard Health Affairs

- Education/ University Hospitals

- King Faisal Specialist Hospital and Research center

- Royal Commission for Jubail and Yanbu

- ARAMCO Hospital

The MOH is the chief governmental health coordinator and has a broad scope of regulatory powers. 
It also allocates global budgets to hospitals through health directories. However, it does not have authority over the other governmental health sectors. The health system has been described as fragmented and this leads to fragmentation of financing for healthcare among these different agencies [16]. These agencies receive more funds per bed than the $\mathrm{MOH}$ and although the $\mathrm{MOH}$ has over demand for services these agencies have extra capacity. Also, physicians at these agencies are usually paid higher than $\mathrm{MOH}$ physicians. These factors may give the perception that the other governmental agencies provide better health services than the $\mathrm{MOH}[17,14]$.

The private sector provides $20 \%$ of services in Saudi Arabia. Prior to the implementation of the Compulsory Employer Based Health Insurance (CEBHI) the major sources of financing for private sector were individual Saudis and private companies. Saudi individuals would pay out of pocket and big private companies would provide voluntary health insurance to their expatriate workers. After implementation of CEBHI, the out of pocket payments decreased by approximately $4 \%$ and there was a huge increase in private insurance more than $10 \%$ as a percentage of private sector expenditure on health. The actual proportion of private expenditure from total health expenditure changed from $18 \%$ in 2006 to $22 \%$ in 2008. However, the percentage remains low [16].

\section{Problems in Saudi Arabia}

In the KSA, financing the national health system is one of the major challenges that the government faces. In spite of an increased budget allocation for these free services, the actual average expenditure per capita is expected to decrease. This is a result of a rapidly growing population and declining government revenues[18]. Free healthcare has led to overutilization and abuse of services. Patients can demand for services and referrals even if they are unnecessary. Health professionals in the public sector are reimbursed on a salary basis and there is no incentive for them to control cost. Many of the Kingdom's hospitals are highly equipped and sophisticated procedures are used for minor problems. The lack of penalties for inefficient use of resources and the tendency of physicians to provide the best technical quality of care may contribute to the problem of overutilization with uncertain benefit [19]. The lack of existing coordination between the different governmental health sectors coupled with no budgetary incentives for cost sharing is another problem. This has reduced the possibility of sharing equipment between different facilities and health sectors. Consequently, expensive capital equipment is underutilized in the Kingdom [14]. Saudis growing use of the private health sector may signal dissatisfaction with the public free care [18].
Another challenge that the Saudi health sector faces is its high dependence on expatriate health professionals as they make up $61 \%$ of the health work force [8]. This creates a problem of continuity and high turnover rates as the average tenure for foreign health professionals is only 2.3 years [14]. Saudi Arabia continues to invest in educational facilities and in the training of doctors abroad to reduce dependency on foreign doctors and other healthcare professionals [8]. Despite these efforts it is unlikely that Saudi Arabia will reach self-sufficiency in the supply of health professionals in the near future. The government might need to reconsider the rule of "Saudization" as its reliance on foreign health workers will increase [20]

There is an imbalance of healthcare provision in different areas in the kingdom. Most health centers and some hospitals operate in rented buildings that are old and unsuitable and do not meet the design requirements of a model healthcare facility. On the other hand, there are a number of hospitals and facilities as military hospitals, university hospitals, and some private hospitals that have state-of-the-art equipment, and highly qualified and professional staff. Also, specialized hospitals are concentrated in large urban areas. Those who live in remote villages and small cities have problems accessing these hospitals [21, 12].

Al Borie and Damanhouri used the SERVQUAL instrument to evaluate inpatient's satisfaction of service quality in public $(\mathrm{MOH})$ and private hospitals in five regions in the kingdom. There were significant differences in the service quality according to hospital type, public or private. Private hospitals' service quality was rated as higher than public and these differences were statistically significant. Public hospitals ranked lowest in specialized medical services, patients dealing with hospitals and employee cooperation with patients. The study did not differentiate between responses of Saudis and non-Saudis [22].

The primary care model that the MOH follows has been successful in increasing access to healthcare especially maternity health, immunization and control of endemic diseases. However, this model has concurrently led to longer waiting lists for hospitals, overutilization of emergency departments and increased use of private health services. The waiting time for nonemergency surgeries in public hospitals can be several months to a year. This is another reason why the public perceives the private sector and other governmental health sectors better than the MOH [14].

AL-Ahmadi and Martin [23], studied the quality of primary healthcare in Saudi Arabia using a systematic search strategy. They concluded that the primary healthcare program in Saudi Arabia has achieved success mainly in access to and effectiveness of traditional primary care services including 
immunization, maternal health and control of endemic diseases. Chronic disease management on the other hand, showed substantial variation. For example, only a small percentage of registered patients with hypertension sought treatment in primary care centers. This was attributed to several reasons including poor professional skills reflected in misdiagnosing and mismanagement of chronic diseases such as hypertension, diabetes, asthma and mental disorders. Another factor is the shortage of community educators as only $8 \%$ of the primary care centers are adequately staffed for health education. Quality of care is also affected by lack of adherence to evidence based guidelines, poor prescribing practices and inappropriate referral patterns (mainly under referring). This has been linked to poor dissemination of evidence based guidelines and poor professional development strategies as many doctors reported never having an educational leave and others do not have access to the Internet or periodical journals. The quality of interpersonal care varied substantially. This was strongly related to language barriers and cultural gaps between doctors and patients. Eighty percent of primary care physicians are expatriates and many of them might not speak Arabic, the language of the majority of patients. In addition doctors found it difficult to relate to some patients because of low levels of education in the community, lack of compliance and patients insistence on receiving medication or being referred to a hospital. This was exacerbated by short consultation times, which one study found to be 5 minutes on average, lower than the international standards. The study identified lack of effective leadership in primary care. Sixty five percent of technical supervisors, who are responsible for overseeing the activities of health centers, had not received managerial training and $85 \%$ had no post graduate qualification. They also had limited roles and unclear expectations. Primary care physicians reported a stressful work environment and patient overload (5060 patients in 8 hours). Expatriate physicians reported additional sources of stress such as income, contract conditions and cultural differences [23].

\section{Health system reform Saudi Arabia}

Until 1999, most Saudi citizens and expatriates had received free healthcare services from the public sector [21].The free- service model with vast population growth has led policy makers to realize that the existing model for healthcare financing and delivery are not efficient nor sustainable [20]. The decision was made to transition from a welfare-oriented National Health Service model to a National Health Insurance model. The first step was taken by the passage of the Cooperative Health Insurance Act of 2003. The health insurance program is based on the Islamic insurance concept "Takaful" which is different than the conventional insurance. The Cooperative Health Insurance is a nonprofit plan based on the concept of cooperation and spreading the risk among members of the community. The act also established the Council of
Cooperative Health Insurance (CCHI). The role of $\mathrm{CCHI}$ includes the preparation of the executive bylaws, certification of the cooperative insurance companies, accreditation of "private \& public" health care providers centers and the definition of the cooperative insurance financial regulation and fees. The act recommended Compulsory Employment Based Health Insurance (CEBHI) [16, 24]. The implementation of the Cooperative Health Insurance scheme was planned over three stages. First, all employers in the private sector are required to provide health insurance for their employees both Saudi and non-Saudi. Implementation of this stage started in 2006 and was done in three phases. The first phase covered companies with 500 or more employees, the second phase covered those with more than 100 workers and the third included all employees of companies in Saudi Arabia including domestic workers. In the second stage, the Cooperative Health Insurance is to be applied for those working in the government sector and in the third stage the Cooperative Health Insurance will be applied to all other groups including Hajj pilgrims. At the completion of the process it is expected that everyone legally in the country will have employer-based health insurance, with exception of the armed forces. Only the first stage has been fully implemented with the government systematically implementing the remaining two stages [13].

Until early September 2013 the type of health insurance to be provided to Saudis was not clear. There had been debate between the Ministry of Health, Shuraa Council and the Health Insurance Council over which type of insurance to require, commercial or social health insurance. By the end of September 2013, the council of health insurance and the council of health services agreed upon social health insurance, very close to the Canadian model. After ample study of the two choices conducted by a number of governmental and private agencies the social health insurance model seemed the most applicable with the Kingdom's health strategy, health policy and labor policy. In addition, the social health system has been one of the most successful, acceptable and equitable systems of health insurance in the world. However, the exact date of implementation has not yet been declared [25]. The Minister of Health, Dr. Abdullah Al Rabeeah, had stated that it is important that the Kingdom provide optimum health insurance that does not add any financial burden to the Saudi citizen. In choosing the best insurance scheme he favored cooperative insurance system as it is aimed at controlling, fine tuning and upgrading the service and reducing waste [26]. The head of the economic affairs in Shura council mentioned that the main goal of health insurance in the kingdom is to provide a third party payer who will bear the expenses of health care services for its members [25]. Umeh [18], had suggested that a national health insurance (NHI) scheme as one of the options for financing healthcare in the kingdom. He mentions that 
the administrative cost of NHI is reasonable especially if the coverage is universal and comprehensive. Contribution is equitable as it will vary with income and it is easier to collect the money, as it will be based on payroll deductions. Universal coverage will eliminate the prospect of a two-tiered healthcare system [18].

Alsharqawi and Abdullah see KSA as unique in its affluent economic status and at the same time is characterized by health problems of a developing nation. Therefore, they recommend that KSA develop its own customized health insurance rather than copying an existing system. They also recommend that Saudi policy makers learn from other countries experience with Social Health Insurance and become aware of its negative effects such as its adverse effects on the labor market [21]. The policy makers have chosen not to go with the commercial insurance model as the one applied in the hybrid United States healthcare system because of its many negative outcomes most importantly linking quality to price. Also, a survey showed that there were only two insurance companies that had expertise in this type of insurance. It is expected that many public hospitals will be privatized and will be able to provide healthcare to insurance holders. The government is looking at creating a governmental fund to finance this system [26, 27].

The goal of this policy change is to increase the participation of the private sector in the health care market and decrease the cost of providing healthcare services on the government. It is also expected to have a positive effect on access to healthcare, effectiveness, efficiency, cost, quality of care, adaptation of new technology and utilization of healthcare services [28].

\section{Compulsory Employer Based Health Insurance in Saudi Arabia}

The Compulsory Employer Based Health Insurance scheme has predetermined minimum health benefits and costs of preparation and repatriation of the corpse of a beneficiary to the home country specified in the labor contract. The health benefits include all costs relating to medical consultation, diagnosis, treatment and medicines as shown in the policy schedule; all costs relating to of hospitalization including surgeries, sameday surgeries or treatment as well as obstetrics and delivery; treatment of dental and gum diseases; and acute psychological disorders within the limits specified in the policy schedule. The benefits also include preventive measures such as vaccinations and maternity and child care services in accordance with instructions issued by the Ministry of Health. Cases of contagious diseases requiring isolation in hospitals as specified by the Ministry of Health are also included. Those eligible for coverage are employees and their dependents (spouse and children 18 years of age and under) if residing in Saudi Arabia [29]. For expats to obtain legal documentation in KSA they need to be covered by health insurance. Expats obtain their health insurance through their employers or sponsors [13]. If the employer does not contract with an insurance plan or fails to pay premiums for his employees he will be required to pay the premium in addition to a fee and may lose his right to employ expatriate workers Cabinet of ministers, 1999.

The health insurance scheme that is applied to the private sector (Saudis and non-Saudis) includes four categories (table 7). Category $\mathrm{C}$ with an average yearly rate of SR 850 (\$226.64) is mostly used by expats. Category B average rate is SR 990 (\$263.97) and category A between SR 1350-1450 (\$359.96-386.63). The highest category is the VIP category with an average rate of SR 2000 (\$533.28). Although all plans cover a range of services from primary to tertiary, they have different benefits and provide different quality of care. Based on database of Council of Cooperative Health Insurance (CCHI), most of the insured foreign labors (low skilled workers) are registered in the basic health plan with annual premium less than SR 1000 (\$267) which offers the basic health coverage as identified by the CCHI in compulsory health insurance policy. The scheme has a fixed predetermined copayment for outpatient and other services. An expatriate must pay an average of $10 \%$ for specialist physician's fee and 30\% consultant physician fees of their salary to cover the copayment cost. The average salary of an expatriate in the private sector was less than $\$ 270$ per month. It is not clear if the average expatriate can afford such payments or if this would be a factor affecting their access to care [16].

During the past year (April-November 2013), the Saudi government has given an amnesty period to all expats who have illegal documents to correct their situation. An expat must obtain health insurance coverage from a licensed health insurance company in order for his required identification documents (Iqama) to be issued or renewed. More than 3.2 million expats have taken advantage of this opportunity, which lead to a SR 200 million (\$53.3 million) of profit for insurance companies. Small health insurance companies have been providing individual coverage for these expats, which enables them to obtain health care in the private health sector. These companies are not capable of providing the same level of health services that large insurance companies provide for their employees whether Saudis or expats. The cost for 12 months of health coverage for an individual has ranged between $\$ 94.60$ - \$149.30 At the end of the amnesty period, which ended at the beginning of the new Hijri year (November, $4^{\text {th }}, 2013$ ), expats who have not obtained legal documents will be fined and deported [30].

Perceptions about the health reform in Saudi Arabia Up to this point, the Cooperative health insurance scheme has been mandated for the private sector only with a primary focus on expats. As the 
government is moving forward to implement health insurance for Saudi citizens, it is important that they take into account what the public currently knows and thinks about the current health insurance system. As mentioned, Saudi citizens consider healthcare to be a right and are accustomed to the free service model. Information about the perception of Saudi hospitals could help policy makers form their decisions and anticipate the problems that may arise with the new NHIS. Physicians' perceptions about the proposed policy is of prime importance because of their role as clinical leaders and front line providers they could be a barrier to or a catalyst for the adoption of the new system.

A study was done by King AbdulAziz Center for National Dialogue to reflect the public's opinion on mandatory health insurance. The results showed that $52.2 \%$ of the Saudi population favored mandatory health insurance where the citizen pays monthly fees. Also, $62 \%$ agreed that health insurance would decrease the load on public hospitals. The study also showed that about half of Saudi citizens who do not have health insurance seek treatment in the private sector while the other half goes to the public health sector [26]. This might be an indication that Saudis prefer to pay for health services in the private sector because of quality care or ease of access as compared to the public sector.

Al Naif [28], surveyed two major hospitals in Riyadh to evaluate physicians' perception about health insurance in the Kingdom. The survey showed that physicians believed that access to healthcare was a major issue and that health insurance would solve this problem. They also believed that health insurance will increase the role of the private sector and will encourage competition between providers leading to more regulation and better utilization of health services. As markets tend to focus on expenditure for technological innovation rather than producing the desired set of social outcomes, the author sees that the Cooperative Health Insurance scheme is one of the best possible answers to the problems facing health care in Saudi Arabia as long as it remains cooperative and not competitive [28].

\section{Barriers to implementation of Saudi National Health Insurance}

One of the main barriers to cooperative insurance that has been mentioned is lack of infrastructure for health services, weak health services provided by public and private sector, and the lack of health insurance companies. Other challenges include the community's low level of awareness about health insurance. Also there is limited manpower and specialized workers in healthcare sectors. Duplication of supervision on insurance regulation is another problem [26]. NHIS is deficient in institutional infrastructure, especially regulatory frame works, operational documentation and public awareness about health insurance [21].

Alosaimi et al. [31] conducted a study to examine equity in access to health services typically provided under the basic insurance coverage of the Cooperative Health Insurance Policy among different categories using a cross sectional study design. Accordingly, 600 insured individuals were selected randomly by multistage proportionate systematic random sampling from four insurance categories. The study showed that the perception of poor quality of services was the main barrier to access of health services. This barrier was more commonly reported than financial or logistic barriers such as transportation or obtaining work permission [31].

Another drawback that was observed form the first stage is lack of compliance with the Shariah (Islamic) laws by many insurance companies. This was due to the absence of regulatory bodies and accurate information data and transparency of the cooperative insurance practice, which resulted in numerous disputes, fraud and abuse of insurance policies by all parties involved [24].

Waltson et al. [14] argue that the $\mathrm{MOH}$ hospitals are not prepared for this insurance model from a managerial stand point. These hospitals lack the managerial skills that would allow them to thrive in a competitive environment. There is a dependence of physicians in these facilities to be directors. Most of these physicians are not trained as managers and without appropriate training they will struggle as they their roles require strategic and market analysis and directors coordination of an increasingly complicated and competitive system. In addition, $\mathrm{MOH}$ hospitals lack the managerial structures that are needed to compete such as appropriate budgeting and sophisticated billing systems [14]. Private sector hospitals are concentrated in large urban areas and neglect rural areas even though they have high populations. These areas are also served by a limited number of public hospitals and are not highly specialized as in urban areas. If health services are not expanded to these areas it could be a risk to the health insurance plan as it will likely not improve access to healthcare [22].

\section{Health Insurance Market in Saudi Arabia}

The Saudi Arabian insurance industry has emerged as one of the fastest growing insurance industries across the world. Since 2003, Saudi Arabian Monetary Agency (SAMA) is regulating the Saudi Arabian insurance industry under the Cooperative Insurance Companies Control Law. SAMA's main task is to guarantee that insurance companies satisfy the conditions and the rules regulating the new policy [16, 24]. The Saudi Arabian insurance industry is characterized by high market share competition among 
the smaller players. Health and motor insurance are core products of the Saudi Arabian insurance sector. The health insurance market composes $32 \%$ of the total insurance market in Saudi Arabia. In 2012, Health insurance segment contributed $55 \%$ to the total Gross Written Premium (GPW) of the Saudi Arabian insurance industry [29]. Despite the growth in Saudi Arabia's insurance market, the industry's insurance penetration is low compared to world insurance penetration, which was $6.6 \%$ in 2011 as per the Swiss Re [6]. Backed by new regulations; the health insurance market in Saudi Arabia is expected to experience a healthy growth rate. Health Insurance Gross Written Premium (GWP) reached SR 11,262 Million (US\$ 2,35 Million) in 2012 from SR 9,708 Million in 2011, an increase of $16 \%$. It is expected to reach SAR 21,1 Million (US\$ 5,70 Million) by the end of 2015, growing at a compound annual growth rate (CAGR) of around 19\% during 2011-2015. Since the implementation of CEBHI in 2006, the number of insured persons has been increasing dramatically reaching 8,349,467 in 2010. However, in 2011 the number decreased by 5\%. In 2012, the number decreased by $1.3 \%$ compared to 2011 reaching $7,828,367$ in total $(5,509,876$ expatriates and $2,318,491$ Saudis working in the private sector) by the end of 2012. The CCHI general secretariat is following up with concerned parties to determine the cause of this decrease. On the other hand, the number of accredited health providers increased from 901 in 2008 to 2,130 and the number of licensed health insurance companies in the kingdom reached 28 [32]. A recent economic survey of the Saudi insurance sector revealed that the sector would create between 35,000 to 40,000 job opportunities over the coming decade [33, 24]. Between the years 2005-2009 insurance companies paid eleven billion Saudi riyals ( $\$ 2.93$ Billion) to Saudi hospitals for their health services. Economist expects that when health insurance covers all the Saudi population both private and public, it will save the government health sector more than 38 billion Saudi Riyals ( $\$ 10.1$ Billion) [26].

\section{Healthcare Finance in the Kingdom of Saudi Arabia: A Qualitative Study of Householders' Attitudes.}

The Kingdom of Saudi Arabia (KSA) is a high-income developing country with a landmass of $2,149,690 \mathrm{~km} 2$ and a population of 31,742,308. Healthcare Finance in the Kingdom of Saudi Arabia: A Qualitative Study of Householders' Attitudes is a study conducted with sample of 36 heads of household in Jeddah province of the Mecca region. Qualitative semistructured interviews were carried out to collect information on the views of Saudi households. The evidence showed some dissatisfaction with the provision and quality of current public sector healthcare services, including the availability of appointments, waiting times and the availability of drugs. The households indicated a willingness to contribute to a national insurance scheme, conditional upon improvements in the quality of public sector healthcare services. The results also revealed a variety of preferences and expectations regarding the proposed national health insurance scheme. [17].

\section{METHODOLOGY}

In this paper, we present a summary of the progress made to finance Saudi healthcare and implement health insurance system in the kingdom. A detailed discussion is given for the many challenges and difficulties faced the implementation of this act. An exploratory approach is used as a primary research method to determine the status of financing and the cooperative health insurance system in the kingdom of Saudi Arabia. Our study is mainly based on the rich literature of reformation of financing healthcare system and implementation of national health insurance. This study explores the current structure of financing the Saudi health care system using a systematic review of studies published between 2010 and 2017.

To facilitate the analysis of healthcare financing in Saudi Arabia, I (i) employed a descriptive framework (as outlined later), and (ii) conducted a literature review of related documents, including unpublished reports about the future of healthcare and financing of health services in the Kingdom of Saudi Arabia.

\section{RESULTS}

Healthcare funding in the KSA has made considerable improvement over the past three years at all tiers of health services. Like several nations, there are three significant characteristics affecting healthcare financing in Saudi Arabia: (i) Large expatriate populations compared to the national population, which leads the Kingdom to use various methods to monitor expatriate healthcare spending; (ii) substantial government revenue, correspondingly high government expenditure on healthcare services; and (iii) substantial government revenue.

Saudi Arabia is one of the few GCC countries (Gulf Council Countries) to have changed its private healthcare system and limited access to government services for expatriates. If CEBHI proves to be a successful scheme to increase expatriate access to medical care, it could be adapted by other GCC countries, not least because most GCC countries are currently looking at various mechanisms to fund their healthcare services.

\section{CONCLUSIONS AND RECOMMENDATIONS}

Saudi Arabia is facing the challenge of providing quality healthcare to its vastly growing population. Financing healthcare has become more challenging for the government as cost continue to rise 
and the incidence of lifestyle related disorders increase. Collectively, the kingdom is moving toward expanding its healthcare infrastructure and increasing the participation of the private sector in both financing and providing healthcare.

Saudi Arabia is following the GCC trend. In fact, KSA was the first of the GCC countries to introduce mandatory health insurance for the private sector with a focus on expats. The first step of healthcare reform came by the implementation of the Cooperative Health Insurance Act of 2004. Transitioning form, a National Healthcare system into a National Health Insurance system was planned on three stages. The first stage has taken effect and employerbased health insurance is now mandatory in the kingdom. All expats in the Kingdom are required to have health insurance coverage in order to issue or renew their legal documentation of residency (Iqama). The policy makers are still learning lessons from the first stage and studying the best way to proceed with national health insurance coverage.

The Saudi experience with health insurance has been successful in providing access to healthcare services for expats. This is evident from the rising number of insured persons from year to year and the rapid growth of the health insurance market. Before implementation of this policy, the expat population had difficulty accessing health services. Expats had to pay out of pocket in the private sector for healthcare. As many of them have low wages and had to pay full charges, they would defer seeking medical treatment except for extreme emergencies. However, the system is still developing and is facing many challenges. Although access has increased, the quality of the services provided remains low especially for expats who are usually enrolled in the basic health insurance plans. There are financial concerns regarding the copayments that expats have to pay and this is an area that requires further evaluation.

One of the obstacles to expanding the health insurance system to Saudis is the low level of awareness about health insurance. The only type of insurance that is allowed in Islam is the cooperative insurance scheme. As a religious country, many citizens might not be aware of the nature of health insurance in the kingdom and might be resistant to it due to a perception that it is against the teachings of Islam. Therefore, there should be efforts to educate the public about the cooperative health insurance scheme and how it follows the teachings of Islam. The CCHI has built a relationship with the media to convey its mission, values and its roles.

Another concern is the weak health insurance infrastructure in the Kingdom. The CCHI is developing initiatives to address these concerns. Currently, CCHI is working on improving electronic communication and exchange of information between various parties. There recent initiative, Saudi Health Insurance Bus (SHIB) is a national project that will standardize, and enable stakeholders to electronically exchange health insurance transactions in a secure and reliable manner that will positively impact the health insurance business. The CCHI is encouraging health insurers and healthcare providers to apply ICD-10-AM coding system by the year 2014. The council is currently providing training sessions for use of ICD-10-AM and disease related groups (AR-DRG) and has made it mandatory for accreditation and reaccreditation [32].

The expansion of healthcare infrastructure, by building new hospitals and clinics, will increase job opportunities for Saudi health professionals. It has been suggested that the private sector will prefer to employ expat health professionals as they have lower wages. On the other hand, the government requires a certain quota of Saudis in each facility. Eventually, Saudi health professionals might find themselves competing with expats for jobs.

As the health insurance scheme expands, there will be an extra demand for trained health managers and administrators. Many Saudi universities have incorporated a department of health administration within their schools of business. It is important to have Saudi health managers to decrease the dependence on foreign managers. Although it will take time to develop enough Saudi health managers to meet the demand. As many health managers currently are Saudi physicians, there should be an emphasis on providing them with adequate managerial training to be able to handle the changes of the new system.

With the increase prevalence of lifestyle related disorders, the new scheme should focus on emphasizing disease prevention and health promotion to enhance public health. Indeed, there is a need for new technologies and advanced treatments but prevention must remain the main focus to prevent an endless demand on specialized treatment and consequently higher costs.

There seems to be consensus on the need for stringent government regulation and supervision of the new health insurance scheme to ensure that it achieves not only its goal of cost shifting but also increasing access and insuring quality of healthcare to all Saudis and expat workers. The CCHI and SAMA are both working to insure proper operation of the cooperative health insurance scheme. As health insurance is still maturing in Saudi, lessons are being learned and regulations are forming accordingly.

The public health relevance of this topic is based on the assumption that health system reforms are intended to bring out better health outcomes for the populations. As Saudi Arabia is embarking on this 
change, it will be insightful to see if it will achieve the desired effects. Also, providing healthcare for expatriate workers is a challenge in many countries. If Saudi Arabia succeeds in providing quality healthcare to this segment of the population, other countries in the Middle East might follow the Saudi model

\section{REFERENCES}

1. WHO. (2013c). Research for universal health coverage

2. Koornneef, E. J., Robben, P. B., Al Seiari, M. B., \& Al Siksek, Z. (2012). Health system reform in the Emirate of Abu Dhabi, United Arab Emirates. Health Policy, 108(2-3), 115-121. doi: 10.1016/j.healthpol.2012.08.026

3. Saltman, R. B., \& Figueras, J. (1998). Analyzing the evidence on European health care reforms. Health Affairs, 17(2), 85-108.

4. CIA. (2013). World Fact Book 2013 from https://http://www.cia.gov/library/publications/theworld-factbook/geos/sa.html

5. IMF. (2013). Saudi Arabia Retrieved 09/2013, from http://www.IMF.Org

6. Ejaz, S. (2013). Saudi Arabian Insurance Industry. Capital Standards, 1-11.

7. WHO. (2010). Mortality: Road traffic deaths by country. Global Health Observatory Data Repository.

8. WHO. (2013d). Saudi Arabia, Country Cooperation Startegy at a glance. 09/2013, from http://www.who.int/countries/sau/en/

9. Alawi, A., \& Alkhazim, M. (2012). Healthcare Policies in GCC: Challenges and Future Directions. The 2012 Gulf Research Meeting. Retrieved 09/2013, 2013, from grm.grc.net

10. Mourshed, M., Hediger, V., \& Lambert, T. (2006). Gulf Cooperation Council Health Care: Challenges and Opportunities. Global Competitiveness Reports.

11. Informa Exhibitions, L. S. (2013). Healthcare in the GCC: A Snapshot Hospital Build \& Infrastructure Magazine, 10-13.

12. Al-Yousuf, M., Akerele, T. M., \& Al-Mazrou, Y. Y. (2002). Organization of the Saudi health system. East Mediterr Health J, 8(4-5), 645-653.

13. Almalki, M., Fitzgerald, G., \& Clark, M. (2011). Health care system in Saudi Arabia: an overview. East Mediterr Health J, 17(10), 784-793.

14. Walston, S., Al-Harbi, Y., \& Al-Omar, B. (2007). The changing face of healthcare in Saudi Arabia. Annals of Saudi Medicine, 28(4), 243-250.

15. WHO. (2011). Health Financing Global Health Observatory Data Repository. World health report 2013 (pp. 168).

16. Alkhamis, A., Hassan, A., \& Cosgrove, P. (2013). Financing healthcare in Gulf Cooperation Council countries: a focus on Saudi Arabia. International Journal of Health Planning and Management. doi: 10.1002/hpm. 2213
17. Al-Hanawi Mohammed Khaled, Omar Alsharqi, Saja Almazrou, \&Kirit Vaidya (2018). Healthcare Finance in the Kingdom of Saudi Arabia: A Qualitative Study of Householders' Attitudes. Applied Health Economics and Health Policy.

18. Umeh, J. C. (1995). Healthcare financing in the Kingdom of Saudi Arabia: a review of the options. World Hospitals and Health Services, 31(2), 3-8.

19. Mufti, M. H. (2000). Healthcare development strategies in the Kingdom of Saudi Arabia: Springer.

20. Khaliq, A. A. (2012). The Saudi health care system: a view from the minaret. World Health Popul, 13(3), 52-64.

21. Al-Sharqi, O. Z., \& Abdullah, M. T. (2012). "Diagnosing" Saudi health reforms: is NHIS the right "prescription"? International Journal of Health Planning and Management. doi: 10.1002/hpm.2148

22. Al-Borie, H. M. (2013). Patients\&apos; satisfaction of service quality in Saudi hospitals: a SERVQUAL analysis. International Journal of Health Care Quality Assurance, 26(1), 20-30.

23. AL-Ahmadi, H., \& Martin, R. (2005). Quality of primary health care in Saudi Arabia: a comprehensive review. International Journal for Quality in Health Care, 17(4), 331-346.

24. Barakah, D. M., \& Alsaleh, S. A. (2011). The Cooperative Insurance in Saudi Arabia: A Nucleus to health Reform Policy. Paper presented at the 2011 International Conference on Information and Finance.

25. Al Zughaibi, A. (2013). Lifting the health insurance system for citizens to the Council of Ministers. ALyoum. Retrieved from http://www.alyaum.com/News/

26. Al Rashidi, S. (2013). Government health insurance. Pains and hopes. Administrative development.

27. Arabiya, A. (2013). Saudi Arabia is considering the establishment of a fund to finance the government health insurance. Retrieved 10/2013, from http://www.alarabiya.net

28. Alnaif, M. S. (2006). Physicians perception of health insurance in Saudi Arabia. Saudi Medical Journal, 27(5), 693-699.

29. CCHI. (2009). Cooperative Health Insurance Policy (Amended). Retrieved 11/2013, from http://www.cchi.gov.sa

30. Al Bogami, S. (2013). Saudi Arabia: the deadline for corrective labor Violation check for $\$ 53$ million companies

31. Alosaimi, M., Alsharif, A., \& Y, M. (2009). The equity in access to health services in cooperative health insurance system, Jeddah, 2008-2009.

32. CCHI. (2012). Council of Cooperative Health Insurance Annual Report 2012.

33. Ahmed, M., \& Damrah, I. (2013). Kingdom of Saudi Arabia , Healthcare Overview Retrieved 09/2013, from

http://www.colliers.com/ /...overview/ksahealthcareo verviewcihq12012.ashx. 